\title{
High Impact Requirements Engineering
}

\section{DOI 10.1007/s12599-010-0098-4}

\section{The Authors}

\author{
Prof. Dr. Matthias Jarke ( $\varangle)$ \\ RWTH Aachen University \\ and Fraunhofer FIT \\ Ahornstr. 55 \\ 52056 Aachen \\ Germany \\ jarke@dbis.rwth-aachen.de
}

Prof. Kalle Lyytinen Ph.D.

Department of Information Systems

Weatherhead School

of Management

Case Western Reserve University

Cleveland

OH 44106-7235

USA

kalle@po.cwru.edu

Published online: 2010-04-15

This article is also available in German in print and via http://www. wirtschaftsinformatik.de: Jarke $M$, Lyytinen K (2010) High Impact Requirements Engineering. WIRTSCHAFTSINFORMATIK. doi: $10.1007 /$ s11576-010-0218-2.

(C) Gabler Verlag 2010
Despite undoubted success in the last two decades, requirements engineering (RE) needs a better alignment between its research focus and its practical grounding. The RE environment now involves elements that were not there 20 or 30 years ago. First, the economics of RE has changed. Large business and technical systems need more rigorous analysis of Return-on-Investment (ROI), but time horizons for ROI have reduced to 18 or 20 month made feasible by massive reuse. Second, there is practically no greenfield software development anymore; RE acts more like Janus, the ancient Roman god of gates - with one face looking at new business and technological challenges and opportunities; and another face gazing at legacy technological, organizational, social and political environments. Third, the scaling towards IT-supported ecosystems results in exceedingly complex and non-linear dynamic dependencies between system components and their natural, technical and social environment - "green IT" being just one of the buzzwords that characterize this trend. Fourth, agility and time to market, low-cost iterative design or even end-user development have become critical factors that lead to the search for new trade-offs between efficiency, openness, and flexibility during requirements capture. Increased outsourcing and offshoring require disciplined evolution and management of specifications as a basis for delegation. Fifth, RE cuts across other forms of design, including industrial design (e.g., pervasive applications), media design (e.g., e-commerce and entertainment), interaction design (e.g., new modalities of interaction), and business environment design (e.g., open business platforms). In summary, a new systematic Science of Design Requirements Engineering is needed, with systematic processes and strict empirical grounding, as proposed, e.g., in the Design Science initiative advocated by $\mathrm{Al} \mathrm{Hevner} \mathrm{in} \mathrm{a} \mathrm{recent} \mathrm{interview} \mathrm{for} \mathrm{this} \mathrm{journal.}$

In June 2007 and October 2008, we organized two international workshops in Cleveland, Ohio, and Dagstuhl Castle, Germany, to deepen this debate, supported by the US National Science Foundation and the German DFG. Summarizing intensive debates (Lyytinen et al. 2009 and Jarke et al. 2008) the group involved in the design of the workshops identified four key principles that underlie future requirements processes and influence their successful resolution (Jarke et al. 2010): (1) the intertwining of requirements and contexts, (2) the co-evolution of designs with their ecologies, (3) the dominant role of architectures, and (4) novel ways to control complexity. Each of these will call for new research approaches and design principles inviting the RE community to think carefully their research priorities. The good news associated with this shift is that the importance of RE continues to grow as the arguments and rationale for it are broadening. But, the bad news is that besides the need for a business case for a decent ROI within a shorter time frame, in future RE we need to consider additional viewpoints such as the need for the alignment with business process, understanding organizational capabilities, systematizing customer expectation management, ensuring legal protection against IPR loss or contract violation suits, creating user buy-in, and minimized training costs when justifying your next RE project. The need for interdisciplinary intellectual exchange between diverse communities will further grow along with the observed need for increased diversity in the design of software-intensive systems.

This issue of the BISE journal represents a continuation of this debate, with a strong focus on the bridge between RE theory and practice in complex settings. Upon an open call for papers, we received nineteen submissions. After rigorous review and revisions, four research papers and one state-of-the-art review were accepted for publication. Leite and Cappelli introduce the concept of "software transparency": by goal and dependency modeling customers and users can continuously follow the evolution of software from an RE perspective, thus supporting the intertwining of requirements and design as well as effective evolution. Such a perspective gains additional importance in the complex context of offshore development; Wiener and Stephan propose reverse presentations of the software as a means to facilitate communication in this complex global software development setting, whereas Overhage, Skroch and Turowski define more general success factors for RE methods in offshore development setting, 
thus enabling an evaluation of existing methods for large-scale offshoring projects. Finally, Zickert and Beck address an important gap between the socio-technical RE work and the business context of project management, by linking goal-oriented RE to project costing based on modern versions of the well-known function point method for project estimation.

In many empirically oriented sciences, most notably in medicine, evidence-based approaches have recently taken a more and more prominent role. In their state-of-the-art survey, Goeken and Patas propose such a systematic evidence-based approach as the basis for method choice in requirements engineering, and classify the RE literature from this novel perspective.

The Design Science perspective behind the two workshops is by no means undisputed. One of its most outspoken critics during the workshops was Turing Award winner Fred Brooks, manager of some of the largest early software projects since the 1960's and author of some of the most influential early software engineering books, including "The Mythical Man Month". We are proud to include an interview with him in this issue.

The papers represent a good cross disciplinary sample of the best research the research-practice boundary in RE. We postulate that the trend towards fuzzy contexts in software engineering will further aggravate the need for requirements-level views of what is going on. For example, we expect to see that the management focus for RE will be shifting from structured process organizations and product lines, to capability-based network organizations and communities organized around platform strategies which enable participation, great variability, and rapid innovation. In these networks, valuable contributions stem from bricoleur participants at the "edge" of the network. The distinction between users and developers vanishes. Transparency, innovation, ethics, and aesthetics take precedence over purely functional designs.

We would like to thank all authors and reviewers as well as the efficient personnel in the WI journal office for their contributions, and hope that the readers will enjoy - and join - the debate about the future of requirements engineering.

Matthias Jarke Kalle Lyytinen

\section{References}

Jarke M, Lyytinen K, Mylopoulos J (eds) (2008) Science of design: high-impact requirements for software-intensive systems. http://drops.dagstuhl.de/opus/portals/index. php?semnr=08412. Abruf am 2010-03-18

Jarke M, Loucopoulos P, Lyytinen K, Mylopoulos J, Robinson B (2010) The brave new world of design requirements - four key principles. In: Proceedings of 20th international conference on advanced information systems engineering (CAiSE 2010). Springer, Berlin

Lyytinen K, Loucopoulos P, Mylopoulos J, Robinson B (eds) (2009) Design requirements engineering - a ten-year perspective. Springer, Berlin 